\title{
PRODUTIVIDADE E QUALIDADE DE RAÍZES DA MANDIOQUINHA-SALSA EM DIFERENTES NÍVEIS DE ADUBAÇÃO NPK
}

\author{
Adalton Mazetti Fernandes ${ }^{1}$, Emerson Loli Garcia ${ }^{1}$, Magali Leonel ${ }^{1}$, Lydia Helena da Silva de Oliveira Mota ${ }^{1,2}$ \\ ${ }^{1}$ Universidade Estadual Paulista - UNESP, Centro de Raízes e Amidos Tropicais - CERAT, Botucatu, SP. E-mail: \\ adalton.fernandes@unesp.br \\ ${ }^{2}$ Instituto Federal de Educação, Ciência e Tecnologia do Acre - IFAC, Cruzeiro do Sul, AC.
}

\section{RESUMO}

As raízes da mandioquinha-salsa possuem elevado valor nutricional, sendo ricas em carboidratos, minerais, vitaminas $\mathrm{A}$ e $\mathrm{C}$, e amido de alta digestibilidade. No entanto, nessa cultura um dos fatores decisivos para a produção de raízes com alto valor nutricional é a fertilização equilibrada. Assim, objetivou-se com este estudo avaliar a produtividade e a qualidade nutricional das raízes de reserva da cultura da mandioquinhasalsa, cultivada sob diferentes níveis de adubação NPK. O experimento foi instalado no delineamento de blocos ao acaso, com oito repetições. Os tratamentos foram constituídos por três níveis de adubação NPK ( $A D 0$ = cultivo sem adubação; AD1 = cultivo com 50\% da adubação NPK recomendada e AD2 = cultivo com $100 \%$ da adubação NPK recomendada). Cada parcela experimental foi constituída por cinco fileiras de plantas de seis metros de comprimento. Concluiu-se que maiores níveis de adubação NPK aumentam o número, o tamanho e a produtividade comercial das raízes de reserva da mandioquinha-salsa. A adubação NPK aumenta o tamanho e a qualidade nutricional de $\mathrm{K}, \mathrm{Mg}$ e $\mathrm{Mn}$ das raízes de reserva, sem interferir no pH da polpa e nos teores de proteína, $\mathrm{Ca}, \mathrm{Cu}$ e Fe. O aumento no tamanho das raízes de reserva em resposta a adubação NPK diminui os seus teores de amido, P e Zn somente se a adubação NPK não aumentar os seus teores de matéria seca.

Palavras-chave: Arracacia xanthorrhiza; amido; concentração de nutrientes; matéria seca; proteína.

\section{ROOT YIELD AND QUALITY OF ARRACACHA IN DIFFERENT NPK FERTILIZATION LEVELS}

\begin{abstract}
The storage roots of arracacha have high nutritional value, being rich in carbohydrates, minerals, vitamins $A$ and $\mathrm{C}$, and starch of high digestibility. However, in this crop one of the decisive factors for the production of roots with higher nutritional value is the balanced fertilization. The aim of this study was to evaluate the yield and nutritional quality of storage roots of arracacha, grown at increasing levels of NPK fertilization. The experiment was conducted in the randomized blocks design, with eight replications. The treatments consisted of three NPK levels (AD0 = unfertilized cultivation, AD1 = cultivation with 50\% of recommended fertilization, and AD2 = cultivation with $100 \%$ of recommended fertilization). It was observed that higher levels of NPK fertilization increase the number, size and marketable yield of storage roots of arracacha crop. NPK fertilization also increases the size and contents of $\mathrm{K}, \mathrm{Mg}$, and $\mathrm{Mn}$ of storage roots, without interfering with the pulp $\mathrm{pH}$ and contents of protein, $\mathrm{Ca}, \mathrm{Cu}$, and Fe. However, when the increase in root size is not accompanied by an increase in dry matter content, the starch, $\mathrm{P}$, and $\mathrm{Zn}$ contents of the roots reduce with increasing levels of NPK fertilization.
\end{abstract}

Keywords: Arracacia xanthorrhiza; starch; nutrient concentration; dry matter; protein.

\section{INTRODUÇÃO}

A mandioquinha-salsa (Arracacia xanthorrhiza Bancroft) é uma hortaliça de grande importância econômica no Brasil, sendo cultivada principalmente nas regiões Sul, Sudeste e Centro-
Oeste (SEDIYAMA et al., 2009) do país, com destaque para o estado de Minas Gerais que cultiva as maiores áreas com essa espécie tuberosa (SEDIYAMA et al., 2008; GOMES et al., 2010). A cultura apresenta grande importância 
social e econômica, além de ser uma boa opção para o agricultor em razão da alta cotação do produto e da estabilidade do mercado durante quase todos os meses do ano (PÁDUA, 2010). Além disso, suas raízes de reserva são excelentes fontes de alimento com considerável valor nutricional, pois possuem cerca de $30 \%$ de carboidratos (PÁDUA, 2010), são ricas em minerais (SANTOS, 2000; SEDIYAMA et al., 2009; PÁDUA, 2010), constituem boa fonte de vitaminas A e B (SEDIYAMA et al., 2009) e apresentam amido de alta digestibilidade (CARMO; LEONEL, 2012). Em termos nutricionais, a mandioquinha-salsa se destaca em relação a outras culturas de raízes tuberosas, pois contêm teores de fósforo $(\mathrm{P})$, potássio $(\mathrm{K})$, cálcio $(\mathrm{Ca})$, ferro $(\mathrm{Fe})$ e zinco $(\mathrm{Zn})$ até maiores que os valores tradicionalmente obtidos nos tubérculos frescos de batata (NUNES et al., 2016), fazendo dela importante fonte de minerais na alimentação humana (SANTOS, 2000).

Devido à sua rusticidade, muitas vezes, os agricultores cultivam essa espécie sem o emprego de tecnologias essenciais para a obtenção de elevadas produtividades, de modo que a mandioquinha-salsa tem sido pouco difundida no Brasil (HEID et al., 2015) e normalmente é cultivada em pequenas áreas, com mão de obra familiar (TORALES et al., 2010), em solos de baixa fertilidade e alta declividade (LEBLANC et al., 2008; BARRELLA et al., 2011) e utilizando baixos níveis de insumos como defensivos e fertilizantes (SEDIYAMA et al., 2008). Contudo, para se obter elevadas produtividades nessa cultura, com a produção de raízes longas e cilíndricas, é preciso atender a alguns requisitos de manejo da cultura, dentre os quais pode-se destacar a fertilidade adequada do solo (SANTOS, 2000; NUNES et al., 2016). Pelo fato da cultura poder ser colhida e comercializada com preços relativamente altos o ano inteiro (SEDIYAMA et al., 2009; PÁDUA, 2010; BARRELLA et al., 2011) e apresentar pequena oscilação de preços ao longo do ano (TORALES et al., 2010), alguns produtores têm investido em tecnologias para melhorar a produtividade e a qualidade das raízes produzidas, inclusive no que se refere ao uso de fertilizantes.

A cultura da mandioquinha-salsa absorve quantidades consideráveis de nutrientes do solo (MAGOLBO et al., 2015), dentre eles o K é o elemento extraído em maiores quantidades, com valores da ordem de $233 \mathrm{~kg} \mathrm{ha}^{-1}$, enquanto o nitrogênio (N) é o segundo nutriente mais absorvido pela cultura cuja absorção, para um nível de produtividade de raízes de $21,3 \mathrm{t} \mathrm{ha}^{-1}$, fica ao redor de $123 \mathrm{~kg} \mathrm{ha}^{-1}$ de N (MAGOLBO et al., 2015). O fósforo (P) é o nutriente menos absorvido pela cultura, mas é o que promove os maiores aumentos na produtividade das raízes de reserva (SILVA et al., 1966). Assim, devido à importância de cada elemento na nutrição da planta, o fornecimento equilibrado desses três nutrientes à cultura da mandioquinha-salsa é fundamental para maximizar a produtividade de raízes de reserva.

Pesquisas indicam que a adubação com $\mathrm{N} \mathrm{e}$ $P$ aumentam a produtividade da mandioquinhasalsa (SILVA et al., 1966; MAGOLBO et al., 2015; NUNES et al., 2016), mas pouco se conhece sobre o efeito da adubação conjunta dos nutrientes $\mathrm{N}$, $P$ e $K$ sobre a qualidade físico-química e nutricional da mandioquinha-salsa. Os aumentos no tamanho e na produtividade das raízes de reserva podem causar a diluição dos teores de minerais neste órgão da planta, o que implicaria na necessidade de aumento do consumo na alimentação para manter inalterada a ingestão de minerais. No entanto, pesquisa recente demonstrou que a adubação nitrogenada aumenta o tamanho das raízes de reserva da mandioquinha-salsa sem alterar o número delas por planta $e$ as suas qualidades nutricionais (NUNES et al., 2016). Porém, não se sabe se o fornecimento de $\mathrm{P}$ e $\mathrm{K}$ causa efeito semelhante na produção e qualidade das raízes de reserva dessa cultura. Em batata, que é uma cultura exigente em nutrientes, nos cultivos realizados em solos de baixa fertilidade o fornecimento de $P$ pode aumentar o tamanho, o teor de amido e a produtividade de tubérculos (FERNANDES et al., 2015a, FERNANDES et al., 2015b), sem alterar significativamente a qualidade nutricional dos mesmos (FERNANDES et al., 2015b), enquanto o $\mathrm{K}$ promove aumentos significativos na produtividade, exercendo efeitos positivos sobre o tamanho e o teor de amido dos tubérculos (FERNANDES; SORATTO, 2012). Assim, considerando que a mandioquinha-salsa é uma cultura que absorve quantidades consideráveis de nutrientes do solo (MAGOLBO et al., 2015) e que o conhecimento sobre o efeito de níveis de adubação na produtividade e na qualidade das raízes de reserva ainda é incipiente, torna-se fundamental avaliar essas características, com o intuito de auxiliar no manejo da adubação dessa cultura. 
Dessa forma, objetivou-se com este estudo avaliar a produtividade e a qualidade nutricional das raízes de reserva da mandioquinha-salsa, cultivada com níveis crescentes de adubação NPK em um Latossolo Vermelho de textura arenosa.

\section{MATERIAL E MÉTODOS}

O experimento foi conduzido na Fazenda Experimental da Faculdade de Ciências Agronômicas (FCA-UNESP), localizada no município de São Manuel-SP entre fevereiro e novembro de 2014. O solo do local é um Latossolo Vermelho distrófico (SANTOS et al., 2006), com teores de argila, silte e areia de 104, 24 e $872 \mathrm{~g} \mathrm{~kg}^{-1}$, respectivamente. O clima da região é do tipo temperado mesotérmico, com temperatura média anual em torno de 21 ㅇ e precipitação média pluvial de $1.377 \mathrm{~mm}$. Os dados referentes à precipitação pluvial, temperaturas máximas e mínimas durante a condução do experimento encontram-se na Figura 1.

Antes da instalação do experimento, foram coletadas amostras de solo na camada de 0-20 $\mathrm{cm}$ para determinação das características químicas. Os resultados foram: matéria orgânica $=17 \mathrm{~g} \mathrm{dm}^{-3} ; \mathrm{pH}\left(\mathrm{CaCl}_{2} 0,01 \mathrm{~mol} \mathrm{~L}^{-1}\right)=5,6 ; \mathrm{P}$ (resina) $=6 \mathrm{mg} \mathrm{dm}^{-3} ; \mathrm{K}^{+}=0,7 \mathrm{mmol}_{\mathrm{c}} \mathrm{dm}^{-3} ; \mathrm{Ca}^{2+}=$
$13 \mathrm{mmol}_{\mathrm{c}} \mathrm{dm}^{-3} ; \mathrm{Mg}^{2+}=7 \mathrm{mmol}_{\mathrm{c}} \mathrm{dm}^{-3} ; \mathrm{H}+\mathrm{Al}^{3+}=14$ $\mathrm{mmol}_{\mathrm{c}} \mathrm{dm}^{-3} ; \mathrm{V}=60 \% ; \mathrm{S}=11 \mathrm{mg} \mathrm{dm}^{-3} ; \mathrm{B}=0,11$ $\mathrm{mg} \mathrm{dm}{ }^{-3} ; \mathrm{Cu}=8,1 \mathrm{mg} \mathrm{dm}^{-3} ; \mathrm{Fe}=11 \mathrm{mg} \mathrm{dm}^{-3} ; \mathrm{Mn}=$ $0,9 \mathrm{mg} \mathrm{dm}^{-3} ;$ e $\mathrm{Zn}=0,4 \mathrm{mg} \mathrm{dm}^{-3}$.

$O$ experimento foi instalado no delineamento de blocos ao acaso, com oito repetições. Os tratamentos foram constituídos por três níveis de adubação NPK: ADO = cultivo sem adubação; $A D 1=$ cultivo com $50 \%$ da adubação NPK recomendada e AD2 = cultivo com $100 \%$ da adubação NPK recomendada. Cada parcela foi constituída por cinco fileiras de plantas de seis metros de comprimento. No tratamento AD2 $(100 \%$ da adubação recomendada), a adubação de plantio foi feita com $150 \mathrm{~kg} \mathrm{ha}^{-1}$ de $\mathrm{P}_{2} \mathrm{O}_{5}$ (superfosfato triplo) e $120 \mathrm{~kg} \mathrm{ha}^{-1}$ de $\mathrm{K}_{2} \mathrm{O}$ (cloreto de potássio), de acordo com a análise de solo e as recomendações de Monteiro e Peressin (1997). Em cobertura aplicaram-se $60 \mathrm{~kg} \mathrm{ha}^{-1}$ de $\mathrm{N}$ (ureia) parcelados aos 30 e 60 dias após o plantio (DAP) (MONTEIRO; PERESSIN, 1997). No tratamento AD1 foi aplicada metade da dose recomendada, ou seja, $75 \mathrm{~kg} \mathrm{ha}^{-1}$ de $\mathrm{P}_{2} \mathrm{O}_{5}$ (superfosfato triplo) e $60 \mathrm{~kg} \mathrm{ha}^{-1}$ de $\mathrm{K}_{2} \mathrm{O}$ (cloreto de potássio) no plantio e $30 \mathrm{~kg} \mathrm{ha}^{-1}$ de $\mathrm{N}$ (ureia) parcelados aos 30 e 60 DAP.

Figura 1. Precipitação pluvial (ا), e temperaturas máximas (-) e mínimas (-) na área experimental durante o período de cultivo da mandioquinha-salsa no campo. Datas de plantio, adubação nitrogenada de cobertura e colheita.

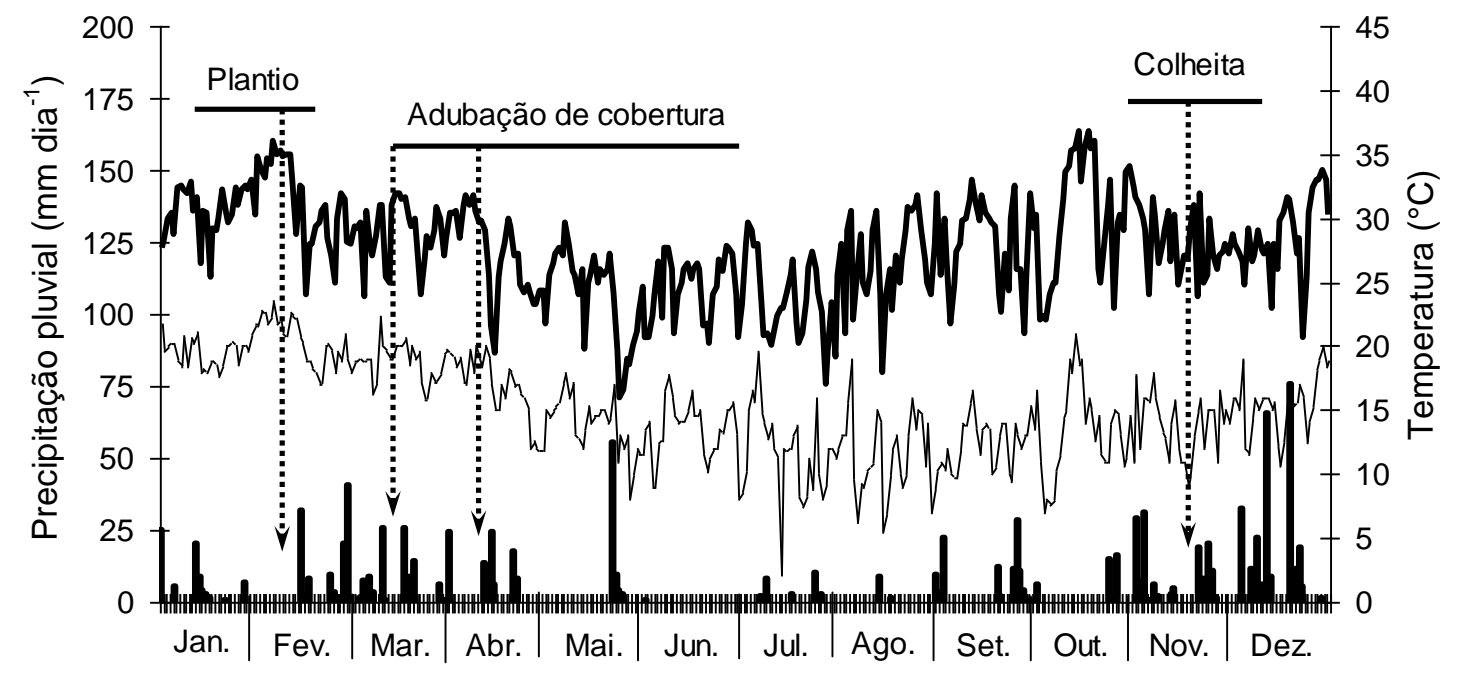

Para o plantio da mandioquinha-salsa o solo foi preparado de forma convencional com uma aração, duas gradagens, seguido do levantamento das leiras com aproximadamente $30 \mathrm{~cm}$ de altura, no espaçamento de $75 \mathrm{~cm}$ entre leiras. Posteriormente, foi realizada a adubação de plantio distribuindo os fertilizantes a $15 \mathrm{~cm}$ de profundidade em sulco contínuo aberto no topo das leiras. Em seguida, os fertilizantes foram incorporados ao solo e os sulcos foram fechados. O plantio da mandioquinha-salsa, cultivar Amarela de Senador Amaral, foi realizado 
utilizando mudas selecionadas de plantas sadias e pré-enraizadas em água, por 30 dias. Antes do pré-enraizamento, as mudas foram tratadas com solução de hipoclorito de sódio a $5 \% \mathrm{v} / \mathrm{v}$, por imersão durante dez minutos. Em seguida, foram cortadas em bisel e acomodadas em potes plásticos de $200 \mathrm{~mL}$, com furos laterais à altura de $2,0 \mathrm{~cm}$. As mudas foram irrigadas diariamente até o plantio, que ocorreu em 12 de fevereiro de 2014. As mudas pré-enraizadas foram transplantadas em covas abertas no topo das leiras, no espaçamento de $30 \mathrm{~cm}$ entre plantas na fileira.

A adubação de cobertura foi realizada aplicando-se as doses de N (ureia) estabelecidas para cada tratamento em filetes contínuos sobre a superfície das leiras e ao lado das plantas. 0 controle de plantas daninhas foi realizado por meio de capina manual, sempre que necessário. A irrigação e o controle fitossanitário foram realizados de acordo com a necessidade e as recomendações técnicas para a cultura na região.

Em 18 de novembro de 2014 (279 DAP) avaliou-se a população final de plantas em duas linhas de cinco metros da área útil de cada parcela. Em seguida, colheram-se duas linhas de 1,8 m (aproximadamente 12 plantas inteiras) na área útil de cada parcela, nas quais determinaram-se o número total e comercial de raízes de reserva por planta. As raízes de reserva foram pesadas para a determinação da massa média total e comercial das raízes. Com os dados de população final de plantas e o peso fresco de raízes por planta calcularam-se as produtividades total e comercial das raízes de reserva. A produtividade comercial foi representada pelas raízes de reserva como massa maior que $25 \mathrm{~g}$ e sem defeitos.

Para as avaliações das qualidades físicoquímicas e nutricionais foram utilizadas quatro raízes de reserva de tamanho comercializável de cada unidade experimental do campo. $\mathrm{Na}$ quantificação dos sólidos solúveis (SS), algumas fatias da polpa das raízes de reserva foram maceradas, e duas gotas do suco foram colocadas no prisma do refratômetro eletrônico modelo PR32; e após um minuto fez-se a leitura direta dos mesmos, sendo expressos em ${ }^{\circ}$ Brix. Para determinação da acidez titulável, $10 \mathrm{~g}$ de polpa triturada foram diluídos em $100 \mathrm{~mL}$ de água destilada, e a mistura foi filtrada e titulada com solução de hidróxido de sódio a 0,1 N, tendo-se utilizado como indicador a fenolftaleína (ZENEBOM; PASCUET, 2005).

A determinação do $\mathrm{pH}$ foi realizada com 10 $\mathrm{g}$ de polpa, triturados em $100 \mathrm{~mL}$ de água destilada, em que foi feita a leitura direta do $\mathrm{pH}$, com medidor de $\mathrm{pH}$ digital, modelo DM-2 (ZENEBOM; PASCUET, 2005).

O teor de matéria seca nas raízes de reserva foi determinado por secagem da polpa das raízes em estufa a $65^{\circ} \mathrm{C}$, com circulação de ar até peso constante. Os teores de amido foram determinados na matéria seca das raízes, segundo metodologia de Somogyi, adaptada por Nelson (1944), e as leituras foram realizadas em espectrofotômetro a $535 \mathrm{~nm}$. O teor de proteína nas raízes de reserva foi determinado na matéria seca, por meio da determinação do nitrogênio total (MALAVOLTA et al., 1997) e utilizando o fator de 6,25 para conversão em proteína bruta. Em seguida, os dados de teores de amido e proteína foram convertidos para teores na matéria fresca. Os teores de minerais foram determinados nas amostras secas (MALAVOLTA et al., 1997) e os valores obtidos convertidos para $\mathrm{mg}$ por $100 \mathrm{~g}$ de matéria fresca.

Os dados obtidos foram submetidos à análise de variância e as médias dos tratamentos foram separadas pelo teste $\mathrm{t}(p \leq 0,05)$. Foram realizadas análises de correlação simples entre os parâmetros de produtividade e as características nutricionais das raízes de reserva, visando determinar o grau de associação entre elas.

\section{RESULTADOS E DISCUSSÃO}

A população final de plantas da mandioquinha-salsa no tratamento com metade da adubação NPK recomendada (AD1) foi maior que nos tratamentos sem adubação (controle) e com a aplicação da dose recomendada (Tabela 1). A menor população de plantas no tratamento com a adubação NPK recomendada não deve estar relacionada com o efeito salino dos fertilizantes, uma vez que foi realizada a incorporação dos fertilizantes ao solo antes do plantio das mudas. 
Tabela 1. Características de produtividade, composição físico-química e nutricional de raízes de mandioquinha-salsa cultivada em diferentes níveis de adubação.

\begin{tabular}{|c|c|c|c|}
\hline \multirow{2}{*}{ Características } & \multicolumn{3}{|c|}{ Tratamentos $^{(1)}$} \\
\hline & ADO & AD1 & AD2 \\
\hline População final de plantas (pl ha ${ }^{-1}$ ) & $23.030 c$ & $40.000 a$ & $26.667 b$ \\
\hline Número total de raízes por planta (no.) & $4,7 b$ & 5,5ab & $6,3 a$ \\
\hline Número de raízes comerciais por planta (no.) & $2,3 c$ & $3,1 b$ & $4,5 a$ \\
\hline Massa média total das raízes (g) & $29,3 c$ & $44,0 b$ & $65,5 a$ \\
\hline Massa média das raízes comerciais (g) & $47,0 c$ & $67,3 b$ & $80,0 a$ \\
\hline Produtividade total de raízes $\left(\mathrm{kg} \mathrm{ha}^{-1}\right)$ & $3.028 b$ & $9.421 a$ & 10.510a \\
\hline Produtividade comercial de raízes $\left(\mathrm{kg} \mathrm{ha}^{-1}\right)$ & $2.450 c$ & $8.107 b$ & $9.517 a$ \\
\hline Teor de matéria seca (\%) & $29,0 a$ & $25,5 b$ & $24,9 b$ \\
\hline Amido (\%) & $24,1 a$ & $21,6 a b$ & $20,8 b$ \\
\hline Sólidos Solúveis ( ${ }^{\circ} \mathrm{Brix}$ ) & $10,0 a$ & $9,1 b$ & $8,4 c$ \\
\hline Acidez titulável & $1,56 a$ & $1,66 a$ & $1,32 b$ \\
\hline pH da polpa & $6,8 \mathrm{a}$ & $6,8 a$ & $6,8 a$ \\
\hline Proteína (\%) & $0,90 a$ & $0,83 a$ & $0,78 a$ \\
\hline$P\left(m g 100 g^{-1}\right)$ & $102 a$ & $94 b$ & $89 b$ \\
\hline $\mathrm{K}\left(\mathrm{mg} 100 \mathrm{~g}^{-1}\right)$ & $468 b$ & $478 \mathrm{~b}$ & $569 a$ \\
\hline $\mathrm{Ca}\left(\mathrm{mg} 100 \mathrm{~g}^{-1}\right)$ & $51 a$ & $50 a$ & $52 a$ \\
\hline $\mathrm{Mg}\left(\mathrm{mg} 100 \mathrm{~g}^{-1}\right)$ & $23 b$ & $21 b$ & $33 a$ \\
\hline $\mathrm{Cu}\left(\mathrm{mg} 100 \mathrm{~g}^{-1}\right)$ & $0,11 a$ & $0,12 a$ & $0,10 a$ \\
\hline $\mathrm{Fe}\left(\mathrm{mg} 100 \mathrm{~g}^{-1}\right)$ & $4,58 a$ & $4,14 a$ & $4,52 a$ \\
\hline $\mathrm{Mn}\left(\mathrm{mg} 100 \mathrm{~g}^{-1}\right)$ & $0,17 c$ & $0,21 b$ & $0,38 a$ \\
\hline $\mathrm{Zn}\left(\mathrm{mg} 100 \mathrm{~g}^{-1}\right)$ & $0,51 a$ & $0,44 b$ & $0,45 b$ \\
\hline
\end{tabular}

Médias seguidas de mesma letra na linha não diferem entre si pelo teste $t(P \leq 0,05) .{ }^{(1)} A D 0=$ Cultivo sem adubação NPK; $A D 1$ = cultivo com $50 \%$ da adubação NPK recomendada e AD2 = cultivo com $100 \%$ da adubação NPK recomendada.

O número total de raízes de reserva por planta no tratamento com $100 \%$ da adubação NPK recomendada foi 1,4 vezes maior que no tratamento sem adubação NPK, mas não diferiu do tratamento com $50 \%$ da adubação NPK recomendada, ou seja, a adubação NPK aumentou o número total de raízes das plantas de mandioquinha-salsa (Tabela 1). Nunes et al. (2016) não obtiveram influência da adubação nitrogenada sobre o número total de raízes por planta na mandioquinha-salsa. Assim, no presente estudo, o aumento no número de raízes provavelmente esteve mais relacionado à adubação fosfatada e potássica.

No tratamento com $100 \%$ da adubação NPK recomendada o número de raízes de reserva de tamanho comercializável foi o dobro daquele obtido no tratamento sem adubação e 1,5 vezes maior que no tratamento com $50 \%$ da adubação recomendada (Tabela 1). Esses resultados indicam que apesar da adubação NPK recomendada ter diminuído a população final de plantas, ela aumentou a quantidade de raízes de reserva de tamanho comercializável por planta.

Em média, o tratamento com $100 \%$ da adubação NPK recomendada apresentou 6,3 raízes de reserva por planta, sendo que destas cerca de 4,5 raízes eram de tamanho comercializável (Tabela 1). Em geral, o número de raízes de reserva por planta varia com as condições de cultivo e os clones utilizados. Nunes et al. (2016), em estudo com a mesma espécie e a mesma cultivar utilizada neste experimento, obtiveram em média 5,6 raízes de reserva por planta. Porém, em estudo com nove clones de mandioquinha-salsa o número médio de raízes de tamanho comercial por planta variou de 0,5 a 6,8 (SEDIYAMA et al., 2009). De acordo com Sediyama et al. (2005) a mandioquinha-salsa produz um número variável de raízes de reserva por planta, geralmente, em número de 4 a 10 raízes.

O tratamento $A D 2,100 \%$ da adubação NPK, aumentou em até 2,2 e 1,7 vezes a massa média total e comercial das raízes de reserva em 
relação ao tratamento sem adubação NPK, respectivamente (Tabela 1 ). Isso demonstra que a adubação NPK além de aumentar o número de raízes por planta também aumenta o seu tamanho, ou seja, a adubação NPK melhora também as características de qualidade das raízes importantes para o processamento (PÁDUA, 2010).

$\mathrm{Na}$ mandioquinha-salsa, a adubação nitrogenada aumentou o tamanho das raízes de reserva sem alterar seu número (NUNES et al., 2016), o que indica que os aumentos no número de raízes por planta, obtidos neste estudo, devem estar mais associados a adubação fosfatada e potássica. No tratamento com $100 \%$ da adubação NPK recomendada a massa média total e comercial das raízes de reserva variou entre 65 e $80 \mathrm{~g}$ (Tabela 1). Nunes et al. (2016) obtiveram aumento na massa de raízes de reserva, variando de 54 a 123 g, e na produtividade das mesmas, até doses estimadas de 121 e $148 \mathrm{~kg} \mathrm{ha}^{-1}$ de $\mathrm{N}$, respectivamente.

Nos tratamentos com $50 \%$ e $100 \%$ da adubação NPK a produtividade total de raízes de reserva não diferiu significativamente, mas foi maior que no tratamento sem adubação, no qual a produtividade foi 3,3 vezes menor (Tabela 1). No entanto, a produtividade comercial foi maior no tratamento com $100 \%$ da adubação NPK recomendada, seguida dos tratamentos com $50 \%$ da adubação recomendada e a testemunha, sem adubação NPK (Tabela 1). No tratamento sem adubação a produtividade comercial da mandioquinha-salsa foi 3,9 vezes menor que no tratamento mais produtivo, e a produtividade comercial correlacionou-se positivamente com o número e a massa média das raízes de reserva (Tabelas 1 e 2). Isso indica que apesar da adubação NPK recomendada diminuir a quantidade de plantas por área, ela promove um efeito compensatório sobre o desenvolvimento das raízes de reserva, aumentando os seus números e tamanho, e consequentemente a produtividade comercial (Tabelas 1 e 2). No tratamento com $100 \%$ da adubação NPK recomendada a pequena redução na população de plantas em relação ao tratamento com metade da adubação recomendada não afetou negativamente a produtividade, porque variações pequenas no espaçamento entre fileiras e na população de plantas da mandioquinha-salsa exercem pouca influência sobre o crescimento das plantas e a produtividade de raízes de reserva, porque essa cultura consegue adaptar-se a diferentes condições de ambiente (GRACIANO et al., 2007).

Neste estudo, a produtividade comercial da mandioquinha-salsa no tratamento com $100 \%$ da adubação NPK recomendada (Tabela 1) ficou próxima da produtividade média brasileira e do estado de Minas Gerais, que são de 9,2 e 10 t ha 1 , respectivamente (SEDIYAMA et al., 2009; PÁDUA, 2010). Os níveis de produtividade não foram maiores provavelmente por causa das elevadas temperaturas ocorridas principalmente nos últimos 3,5 meses do ciclo da cultura (Figura 1), pois a ocorrência de elevadas temperaturas na fase de maturação das raízes da mandioquinhasalsa reduz a alocação de MS neste órgão da planta (PÁDUA, 2010).

Em relação às características de qualidade das raízes de reserva, verifica-se que a adubação NPK não interferiu significativamente no $\mathrm{pH}$ da polpa e nos teores de proteína, $\mathrm{Ca}, \mathrm{Cu}$ e $\mathrm{Fe}$ das raízes de reserva, e estas variáveis não se correlacionaram com a massa média das raízes de reserva (Tabelas 1 e 2). Isso indica que a adubação NPK pode aumentar o tamanho e a produtividade de raízes de mandioquinha-salsa sem prejudicar essas características de qualidade. Nunes et al. (2016), avaliaram o efeito da adubação nitrogenada na mandioquinha-salsa e também não observaram influência da mesma nos teores de $\mathrm{Ca}, \mathrm{Cu}$ e $\mathrm{Fe}$ das raízes, mas obtiveram aumento linear nos teores de proteína, possivelmente por causa das elevadas doses de N utilizadas $\left(200 \mathrm{~kg} \mathrm{ha}^{-1}\right.$ ). Contudo, nessa pesquisa, os teores de proteína das raízes de reserva variaram de $0,78 \%$ a $0,90 \%$, os quais se assemelharam ao teor médio de 0,90\% descrito por Santos (2000). 
Tabela 2. Coeficientes de correlação simples $(r)$ e probabilidade $(P)$ das variáveis número, massa média e teor de matéria seca das raízes de reserva com as características de produtividade e qualidade nutricional da mandioquinha-salsa.

\begin{tabular}{|c|c|c|}
\hline Características & $r$ & $P$ \\
\hline & \multicolumn{2}{|c|}{ No. de raízes comerciais por planta } \\
\hline \multirow[t]{2}{*}{ Produtividade comercial $\left(\mathrm{kg} \mathrm{ha}^{-1}\right)$} & 0,63 & $<0,001$ \\
\hline & \multicolumn{2}{|c|}{ Massa média das raízes (g) } \\
\hline Produtividade comercial $\left(\mathrm{kg} \mathrm{ha}^{-1}\right)$ & 0,79 & $<0,001$ \\
\hline Sólidos solúveis ( ${ }^{\circ}$ Brix) & $-0,74$ & $<0,001$ \\
\hline Acidez titulável & $-0,66$ & $<0,001$ \\
\hline pH da polpa & $-0,02$ & 0,937 \\
\hline Amido (\%) & $-0,53$ & 0,008 \\
\hline Proteína (\%) & $-0,30$ & 0,155 \\
\hline$P\left(m g 100 g^{-1}\right)$ & $-0,64$ & 0,001 \\
\hline $\mathrm{K}\left(\mathrm{mg} 100 \mathrm{~g}^{-1}\right)$ & 0,42 & 0,041 \\
\hline $\mathrm{Ca}\left(\mathrm{mg} 100 \mathrm{~g}^{-1}\right)$ & $-0,04$ & 0,839 \\
\hline $\mathrm{Mg}\left(\mathrm{mg} 100 \mathrm{~g}^{-1}\right)$ & 0,53 & 0,008 \\
\hline $\mathrm{Cu}\left(\mathrm{mg} 100 \mathrm{~g}^{-1}\right)$ & $-0,21$ & 0,324 \\
\hline $\mathrm{Fe}\left(\mathrm{mg} 100 \mathrm{~g}^{-1}\right)$ & 0,01 & 0,951 \\
\hline $\mathrm{Mn}\left(\mathrm{mg} 100 \mathrm{~g}^{-1}\right)$ & 0,89 & $<0,001$ \\
\hline \multirow[t]{2}{*}{$\mathrm{Zn}\left(\mathrm{mg} 100 \mathrm{~g}^{-1}\right)$} & $-0,35$ & 0,090 \\
\hline & \multicolumn{2}{|c|}{ MS das raízes (\%) } \\
\hline Amido (\%) & 0,92 & $<0,001$ \\
\hline$P\left(m g 100 g^{-1}\right)$ & 0,71 & $<0,001$ \\
\hline$K\left(\mathrm{mg} 100 \mathrm{~g}^{-1}\right)$ & 0,16 & 0,460 \\
\hline $\mathrm{Ca}\left(\mathrm{mg} 100 \mathrm{~g}^{-1}\right)$ & 0,69 & $<0,001$ \\
\hline$M g\left(m g 100 g^{-1}\right)$ & $-0,37$ & 0,075 \\
\hline $\mathrm{Cu}\left(\mathrm{mg} 100 \mathrm{~g}^{-1}\right)$ & 0,56 & 0,005 \\
\hline $\mathrm{Fe}\left(\mathrm{mg} 100 \mathrm{~g}^{-1}\right)$ & 0,37 & 0,073 \\
\hline $\mathrm{Mn}\left(\mathrm{mg} 100 \mathrm{~g}^{-1}\right)$ & $-0,42$ & 0,041 \\
\hline $\mathrm{Zn}\left(\mathrm{mg} 100 \mathrm{~g}^{-1}\right)$ & 0,69 & $<0,001$ \\
\hline
\end{tabular}

Nos tratamentos que receberam $50 \%$ e $100 \%$ da adubação NPK recomendada os teores de MS não diferiram, mas diminuíram em relação ao tratamento sem adubação, possivelmente porque o aumento no tamanho das raízes não foi acompanhado de um aumento nas quantidades de sólidos ocasionando assim a diluição da MS de raízes nesses tratamentos (Tabela 1). Em batata, a adubação fosfatada também causou a diluição do teor de MS dos tubérculos (Fernandes et al., 2015b). Esses resultados indicam que características de qualidade das raízes de reserva da mandioquinha-salsa, como o tamanho, a uniformidade, os teores de MS, entre outras, podem ser influenciadas por vários fatores externos, inclusive o sistema de manejo que a cultura é submetida (PÁDUA, 2010). Nunes et al. (2016) verificaram que a adubação nitrogenada na mandioquinha-salsa aumentou a massa das raízes sem diminuir os teores de MS das mesmas. Os teores de amido no tratamento com $100 \%$ da adubação NPK recomendada foram menores que no tratamento sem adubação, mas não diferiram do tratamento com a dose intermediária de fertilizante (Tabela 1). No entanto, somente $100 \%$ da adubação NPK recomendada ocasionou diluição significativa dos teores de amido em relação à testemunha sem adubação NPK, demonstrando que o aumento expressivo no tamanho das raízes em resposta a adubação pode diminuir os teores de amidos nas mesmas, uma vez que a massa média das raízes se correlacionou negativamente com os teores de amido (Tabelas 1 e 2). Em batata, quando a adubação fosfatada aumentou expressivamente o tamanho e a produtividade dos tubérculos também houve efeito de diluição dos teores de MS do órgão de armazenamento (Fernandes et al., 2015b). Porém, os teores de amido e MS das raízes de reserva se correlacionaram positivamente, o que significa que o emprego de técnicas de manejo que favoreçam o aumento no tamanho das raízes, associada a uma maior alocação de MS nas mesmas, pode até 
incrementar os teores de amido das raízes (Tabela 2). Em tubérculos de batata os teores de amido também se correlacionam positivamente com os teores de MS, pelo fato do amido representar entre 60 a $80 \%$ das MS dos tubérculos (FREITAS et al., 2006; FERNANDES et al., 2010; EVANGELISTA et al., 2011).

O teor de sólidos solúveis das raízes de reserva foi maior no tratamento testemunha e reduziu significativamente com o fornecimento da adubação NPK, sendo obtidos os menores valores no tratamento com $100 \%$ da adubação recomendada (Tabela 1). Esse fato indica que neste tratamento os conteúdos de sacarose das raízes eram menores, tendo em vista que os sólidos solúveis são constituídos principalmente por açúcares como a sacarose (EVANGELISTA et al., 2011). Como em batata menores valores de sólidos solúveis não são indicativo de baixa qualidade dos tubérculos (EVANGELISTA et al., 2011), essa redução nos valores de sólidos solúveis das raízes da mandioquinha-salsa em resposta a adubação NPK não deve comprometer negativamente sua qualidade. A acidez titulável não diferiu entre os tratamentos sem adubação e com $50 \%$ da adubação NPK recomendada, mas ambos os tratamentos apresentaram valores de acidez titulável maiores que no tratamento com $100 \%$ da adubação NPK recomendada, o que indica que nestes a quantidade de ácidos orgânicos na polpa das raízes de reserva era maior (Tabela 1). Essa redução nos valores dos sólidos solúveis e da acidez titulável em resposta a adubação NPK é resultado do efeito de diluição ocasionado pelo aumento no tamanho e na produtividade das raízes, tendo em vista que a massa média das raízes de reserva se correlacionou negativamente com sua acidez titulável e sólidos solúveis (Tabelas 1 e 2).

Os tratamentos com 50 e $100 \%$ da adubação NPK proporcionaram menores concentrações de $P$ e $Z n$ nas raízes, demonstrando que o aumento na massa e na produtividade das raízes causou a diluição dos teores desses nutrientes nas raízes, pois a massa média das raízes se correlacionou negativamente com os teores de $\mathrm{P}$ e teve uma tendência de correlação negativa com os teores de $\mathrm{Zn}$ $(P=0,090)$ (Tabelas 1 e 2$)$. No entanto, como a MS das raízes se correlacionou positivamente com os seus teores de $\mathrm{P}$ e $\mathrm{Zn}$, é de se esperar que a adubação NPK só diminua a qualidade nutricional destes nutrientes em condições nas quais a adubação NPK não aumente os teores de MS das raízes (Tabela 2). Em estudo com a aplicação de até $200 \mathrm{~kg} \mathrm{ha}^{-1}$ de $\mathrm{N}$ não se observou alterações nos teores nutricionais de nutrientes como $\mathrm{P}, \mathrm{K}$, $\mathrm{Ca}, \mathrm{Mg}, \mathrm{Cu}, \mathrm{Fe}, \mathrm{Mn}$ e Zn (NUNES et al., 2016).

Neste estudo os teores dos nutrientes $\mathrm{K}$, $\mathrm{Mg}$ e $\mathrm{Mn}$ nas raízes de reserva do tratamento com $100 \%$ da adubação NPK recomendada foram maiores que nos demais tratamentos (Tabela 1). Nos tratamentos com $50 \%$ da adubação NPK recomendada os teores de $\mathrm{K}$ e $\mathrm{Mg}$ não diferiram do tratamento com a maior dose, mas no tratamento sem adubação os teores de $\mathrm{Mn}$ foram menores. Isso indica que a adubação NPK na mandioquinha-salsa além de aumentar o tamanho e a produtividade das raízes de reserva também aumenta a qualidade nutricional de alguns nutrientes como $\mathrm{K}, \mathrm{Mg}$ e $\mathrm{Mn}$, os quais se correlacionaram positivamente com a massa média das raízes (Tabelas 1 e 2). Os teores de $\mathrm{Ca}$, $\mathrm{Cu}$ e $\mathrm{Mn}$ se correlacionaram positivamente com os teores de MS das raízes, indicando que práticas de manejo que aumentem a MS das raízes, consequentemente melhoram a qualidade nutricional das mesmas em relação a esses nutrientes (Tabela 2). Segundo Pádua (2010) solo com boa fertilidade e com uma fertilização adequada de $\mathrm{N}, \mathrm{P}$ e K apresenta efeito favorável tanto sobre a produtividade quanto na qualidade das raízes de reserva da mandioquinha-salsa, tal como observado neste estudo.

Os teores de $\mathrm{P}, \mathrm{K}, \mathrm{Ca}, \mathrm{Mg}, \mathrm{Cu}, \mathrm{Fe}, \mathrm{Mn}$ e $\mathrm{Zn}$ nas raízes de reserva variaram de 89-102, 468569, 50-52, 23-33, 0,10-0,12, 4,14-4,58, 0,17-0,38 e 0,44-0,51 mg $100 \mathrm{~g}^{-1}$, respectivamente (Tabela 1), ou seja, valores estes próximos aos teores de $\mathrm{P}, \mathrm{K}, \mathrm{Ca}, \mathrm{Mg}, \mathrm{Cu}, \mathrm{Mn}$ e $\mathrm{Zn}$ obtidos por Nunes et al. (2016), em estudo com adubação nitrogenada, na mesma cultura. Estes resultados comprovam que as raízes de mandioquinha-salsa além de serem excelentes fontes de minerais como $\mathrm{Ca}, \mathrm{P}$ e Fe (SANTOS, 2000; PÁDUA, 2010), também são ricas em K (NUNES et al., 2016; PÁDUA, 2010) (Tabela 1), fato este, que as tornam importantes fontes de minerais na alimentação humana (SANTOS, 2000; PÁDUA, 2010), com capacidade de fornecer mais $P, K, C a, F e$ e $Z n$ que os tubérculos de batata (NUNES et al., 2016).

\section{CONCLUSÕES}

A adubação NPK aumenta o número, o tamanho e a produtividade comercial das raízes de reserva da mandioquinha-salsa.

A adubação NPK aumenta o tamanho e os teores de $\mathrm{K}, \mathrm{Mg}$ e $\mathrm{Mn}$ das raízes de reserva, sem 
interferir no $\mathrm{pH}$ da polpa e nos teores de proteína, $\mathrm{Ca}$, Cu e Fe.

Quando o aumento no tamanho das raízes não é acompanhado por um aumento no teor de matéria seca, os teores de amido, $\mathrm{P}$ e $\mathrm{Zn}$ das raízes reduzem com os níveis crescentes de adubação NPK.

\section{REFERÊNCIAS}

BARRELLA, T.P.; PUIATTI, M.; SANTOS, R.H.S.; CECON, P.R. Production and mass partitioning in Peruvian carrot plants grown under artificial shading period and intensity. Acta Scientiarum Agronomy, v.33, p.321-326, 2011.

CARMO, E.L.; LEONEL, M. Composição físicoquímica e cor de clones de mandioquinha-salsa. Energia na Agricultura, v.27, p.62-81, 2012. https://doi.org/10.17224/EnergAgric.2012v27n1p $\underline{62-81}$

EVANGELISTA, R.M.; NARDIN, I.; FERNANDES, A.M.; SORATTO, R.P. Qualidade nutricional e esverdeamento pós-colheita de tubérculos de cultivares de batata. Pesquisa Agropecuária Brasileira, v.46, p.953-960, 2011. https://doi.org/10.1590/S0100-

$\underline{204 X 2011000800023}$

FERNANDES, A.M.; SORATTO, R.P. Nutrição mineral, calagem e adubação da batateira. Botucatu: FEPAF, 2012. 121p.

FERNANDES, A.M.; SORATTO, R.P.; EVANGELISTA, R.M. Qualidade de tubérculos de batata da cultivar 'Atlantic' afetada pela adubação fosfatada. Ciência Rural, v.45, p.1401-1407, 2015a. https://doi.org/10.1590/0103$\underline{8478 \mathrm{cr} 20141530}$

FERNANDES, A.M.; SORATTO, R.P.; MORENO, L.A.; EVANGELISTA, R.M. Qualidade de tubérculos frescos de cultivares de batata em função da nutrição fosfatada. Bragantia, v.74, p.102-109, 2015b. https://doi.org/10.1590/1678-4499.0330

FERNANDES, A.M.; SORATTO, R.P.; EVANGELISTA, R.M.; NARDIN, I. Qualidade físico-química e de fritura de tubérculos de cultivares de batata na safra de inverno. Horticultura, v.28, p.299-304, 2010. https://doi.org/10.1590/S0102$\underline{05362010000300010}$
FREITAS, S.T.; BISOGNIN, D.A.; GÓMEZ, A.C.S.; SAUTTER, C.K.; COSTA, L.C.; RAMPELOTTO, M.V. Qualidade para processamento de clones de batata cultivados durante a primavera e outono no Rio Grande do Sul. Ciência Rural, v.36, p.8085, 2006. https://doi.org/10.1590/S010384782006000100012

GOMES, H.E.; HEREDIA ZÁRATE, N.A.; VIEIRA, M.C.; GASSI, R.P.; TORALES, E.P.; MACEDO, R.V. Produção de mudas e de raízes comerciais de mandioquinha-salsa 'Amarela de Carandaí' em função de espaçamentos e amontoa. Semina: Ciências Agrárias, v.31, p.1121-1132, 2010.

GRACIANO, J.D.; HEREDIA ZÁRATE, N.A.; VIEIRA, M.C.; ROSA, Y.B.C.J.; SEDIYAMA, M.A.N. Espaçamentos entre fileiras e entre plantas na produção da mandioquinha-salsa branca. Ciência e Agrotecnologia, v.31, p.1688-1695, 2007. https://doi.org/10.1590/S1413-

$\underline{70542007000600013}$

HEID, DM.M; HEREDIA ZÁRATE, N.A.; VIEIRA, M.C.; TORALES, E.P.; CARNEVALI, T.O.; MARAFIGA, B.G. Produtividade agroeconômica de mandioquinha-salsa em resposta à adição de cama-de-frango no solo. Semina: Ciências Agrárias, v. 36, n. 3, suplemento 1, p. 1835-1850, 2015.

LEBLANC, R.E.G; PUIATTI, M.; SEDIYAMA, M.A.N.; FINGER, L.F.; MIRANDA, G.V. Influência do préenraizamento e de tipos de mudas sobre a população, crescimento e produção da mandioquinha-salsa 'Roxa de Viçosa'. Revista Ceres, v.55, p.74-82, 2008.

MAGOLBO, L.A.; CARMO, E.L.; GARCIA, E.L.; FERNANDES, A.M.; LEONEL, M. Dry matter accumulation and mineral nutrition of arracacha in response to nitrogen fertilization. Pesquisa Agropecuária Brasileira, v.50, p.669-680, 2015. https://doi.org/10.1590/S0100204X2015000800005

MALAVOLTA, E.; VITTI, G.C.; OLIVEIRA, S.A. Avaliação do estado nutricional de plantas: princípios e aplicações. Piracicaba: Potafós, 1997. 308p.

MONTEIRO, D.A.; PERESSIN, V.A. Mandioquinha. In: RAIJ, B.van.; CANTARELLA, H.; QUAGGIO, J.A.; FURLANI, A.M.C. (Ed.). Recomendações de 
adubação e calagem para o Estado de São Paulo. Campinas: Instituto Agronômico de Campinas, 1997. p.229. (Boletim Técnico, 100).

NELSON, N.A. A photometric adaptation of Somogy method for determination of glucose. Journal of Biological Chemistry, v.153, p.375390, 1944.

NUNES, A.R.A.; FERNANDES, A.M.; LEONEL, M.; GARCIA, E.L.; MAGOLBO, L.A.; CARMO, E.L. Nitrogênio no crescimento da planta e na qualidade de raízes da mandioquinha-salsa. Ciência Rural, v.46, p.242-247, 2016. https://doi.org/10.1590/0103-8478cr20150339

PÁDUA, J.G. Produção de batata e mandioquinhasalsa visando o processamento industrial. Revista Raízes e Amidos Tropicais, v.6, p.147-161, 2010.

SANTOS, F.F. VII Encontro nacional da mandioquinha-salsa e I Seminário de integração do fumo, milho e mandioquinha-salsa. Horticultura Brasileira, v.18, p.244-262, 2000.

SANTOS, H.G.; JACOMINE, P.K.T.; ANJOS, L.H.C.; OLIVEIRA, V.A.; OLIVEIRA, J.B.; COELHO, M.R.; LUMBRERAS, J.F.; CUNHA, T.J.F. (Ed.). Sistema brasileiro de classificação de solos. 2. ed. Rio de Janeiro: Embrapa Solos, 2006. 306p.

SEDIYAMA, M.A.N.; SANTOS, M.R.; ALBANEZ, A.C.M.P.; RIBEIRO, J.M.O.; GRANATE, M.J.; VIDIGAL, S.M. Agrosilício na produção de clones de mandioquinha-salsa. Acta Scientiarum Agronomy, v.31, p.427-432, 2009. https://doi.org/10.4025/actasciagron.v31i3.699

SEDIYAMA, M.A.N.; FREITAS, R.S.; PEREIRA, P.C.; SEDIYAMA, T.; MASCARENHAS, M.H.T.; FERREIRA, F.A. Avaliação de herbicidas no controle de plantas daninhas em mandioquinha-salsa. Bragantia, v.67, p.921-926, 2008. https://doi.org/10.1590/s0006-

$\underline{87052008000400014}$

SEDIYAMA, M.A.N.; VIDIGAL, S.M.; GRANATE, M.J.; SANTOS, M.R.; MASCARENHAS, M.H.T. Cultura da mandioquinha-salsa ou batata-baroa. Belo Horizonte: EPAMIG, 2005. 28p. (Boletim Técnico, 77)

SILVA, J.R.; BLANCO, H.G.; NORMANHA, E.S.; FREIRE, E.S. Efeitos de doses crescentes de nitrogênio, fósforo e potássio sobre a produção de mandioquinha-salsa. Bragantia, v.25, p.365369, 1966. https://doi.org/10.1590/S0006$\underline{87051966000200008}$

TORALES, E.P.; HEREDIA ZÁRATE, N.A.; VIEIRA, M.C.; RESENDE, M.M.; SANGALLI, C.M.S.; GASSI, R.P. Doses de cama-de-frango e densidade de plantio na produção de mandioquinha-salsa 'Amarela de Carandaí'. Semina: Ciências Agrárias, v.31, p.1165-1176, 2010. https://doi.org/10.5433/16790359.2010v31n4Sup1p1165

ZENEBOM, O.; PASCUET, N.S. Ministério da Saúde. Agência Nacional de Vigilância Sanitária. Métodos físico-químicos para análise de alimentos. 4. ed. Brasília: Ministério da Saúde, 2005. 1018p.

Recebido para publicação em 06/02/2018 Revisado em 14/08/2018

Aceito em 15/08/2018 